\title{
Atividade antimicrobiana do óleo essencial de alecrim-pimenta e do extrato bruto seco do barbatimão diante de bactérias isoladas do leite
}

\author{
João Paulo Ramos Costa* \\ Anna Christina de Almeida \\ Ernane Ronie Martins \\ Márcio Neves Rodrigues \\ Claudinei Alves dos Santos \\ Isabela Rocha Menezes \\ Universidade Federal de Minas Gerais, Instituto de Ciências Agrárias \\ CEP 39404-006, Montes Claros - MG, Brasil \\ *Autor para correspondência \\ jpramoscosta@hotmail.com
}

Submetido em 03/05/2011

Aceito para publicação em 01/09/2011

\section{Resumo}

O objetivo deste trabalho foi avaliar a atividade antimicrobiana in vitro do óleo essencial do Lippia sidoides (OELs), conhecido popularmente como "alecrim-pimenta", e do extrato bruto seco do Stryphnodendron adstringens (EBSSa), ou "barbatimão", contra bactérias isoladas do leite total de rebanho, provenientes de unidades agrícolas familiares do norte de Minas Gerais. O EBSSa foi obtido a partir da casca do vegetal por extração estática em etanol 99,9\% por oito dias. O OELs foi obtido por meio da hidrodestilação das folhas frescas. As bactérias Escherichia coli e Staphylococcus aureus isoladas de leite foram submetidas aos testes de disco-difusão e concentração bactericida minima (CBM), utilizando as concentrações de 320, 160, 80, 40, 20 e $0 \mu \mathrm{l} / \mathrm{mL}$ do OELs e 400, 200, 100, 50, 25 e 0 mg/mL do EBSSa. Todas as bactérias se mostraram sensíveis aos extratos vegetais, exceto Escherichia coli que não foi inibida pelos dois testes quando foi utilizado o EBSSa.

Palavras-chave: CBM, Coliformes, Lippia sidoides, Plantas medicinais, Stryphnodendron adstringens

\section{Abstract}

Antimicrobial activity of rosemary-pepper essential oil and barbatimao dry crude extract against bacteria isolated from milk. The aim of this study was to evaluate the in vitro antimicrobial activity of Lippia sidoides essential oil (LsEO), popularly known as "rosemary-pepper", and the Stryphnodendron adstringens dry crude extract (SaDCE), or "barbatimao", against bacteria isolated from total milk flock, from small farms of northern Minas Gerais state. SaDCE was obtained from the peel of the vegetable through static distillation in ethanol 99.9\% during eight days. LsEO was obtained through hydro-distillation of its fresh leaves. The bacteria Escherichia coli and Staphylococcus aureus isolated from milk underwent the test of disk-diffusion and minimum bacterial concentration (MBC), using concentrations of 320, 160, 80, 40, 20 and $0 \mu 1 / \mathrm{mL}$ of LsEO and 400, 200, 100, 50, 25 and $0 \mathrm{mg} / \mathrm{mL}$ of SaDCE. All bacteria were sensitive to the vegetable extracts, except the Escherichia coli which was not inhibited by any test when SaDCE was used.

Key words: Coliforms, MBC, Medicinal plants, Lippia sidoides, Stryphnodendron adstringens 


\section{Introdução}

Na cadeia produtiva de leite, a sanidade dos animais e das instalações em que é obtido, assume grande importância na qualidade final do produto. Isso ocorre pelo fato do leite ser um substrato propício ao crescimento de microrganismos ambientais e infecciosos que podem acometer os animais e tornar os derivados impróprio ao consumo humano (GERMANO; GERMANO, 1995; AMABILE, 1999). Dessa forma, a eficiência dos antimicrobianos empregados tem grande importância no tratamento de animais além de protocolos de sanitização dessa atividade (MORAES et al., 1997).

O uso de antimicrobianos sintéticos em demasia levou a um aumento considerável da resistência dos microrganismos a estes compostos (LOPES et al., 1990; NORBBY; NORD, 2005). Diante da necessidade de encontrar novas bases com atividade antimicrobiana como forma de garantir a eficiência do tratamento a bacterioses, nota-se um crescente interesse pelas plantas medicinais como potencial fonte de agentes de novas moléculas bioativas (COHEN, 1992; RIBEIRO et al., 2005).

A bioatividade das plantas medicinais é inerente a um grupo de compostos chamados metabolitos secundários. Estes, são sintetizados a partir de reações catabólicas, anabólicas e da biotransformação a partir dos aminoácidos, carboidratos e lipídios produzidos pela planta. Entre os principais metabólitos secundários, está o tanino, que se destaca pela sua variada atividade biológica (SANTOS; MELLO, 2000).

Muitas plantas tâniferas são conhecidas no Brasil, no entanto, o Stryphnodendron adstringens (Mart.) Coville, conhecido popularmente como "barbatimão", se destaca pela quantidade de taninos na casca que confere suas principais propriedades, entre elas sua significante atividade antimicrobiana sobre Staphyloccocus aureus, Pseudomonas sp., Escherichia coli (TOLEDO, 2002; MACEDO; FERREIRA, 2004).

Outra planta nativa com potencial fonte de moléculas bioativas é a Lippia sidoides Cham. (verbenaceae) ou "alecrim-pimenta", encontrada desde o norte de Minas Gerais até o nordeste brasileiro (MARTINS et al., 2000).
O óleo essencial extraido das folhas frescas dessa planta possui o timol e o carvacrol, constituintes que conferem a atividade antimicrobiana frente a Candisa albicans, S. aureus, bactérias causadoras da cárie dentária, entre outras (OLIVEIRA et al., 2006; BOTELHO et al., 2007).

O objetivo deste trabalho foi avaliar a atividade antimicrobiana in vitro do óleo do alecrim-pimenta e do extrato bruto seco do barbatimão em bactérias isoladas do leite cru.

\section{Material e Métodos}

O material vegetal para a extração do óleo essencial de Lippia sidoides (OELs) foi coletado no horto medicinal na fazenda experimental do instituto de Ciências Agrárias da UFMG em Montes Claros (MG). O OELs foi obtido por meio da técnica de hidrodestilação de folhas fresca em aparelho de Clevenger (GUENTHER, 1972). Para o preparo do extrato bruto seco de Strypnhodendron adstringesn (EBSSa) foi utilizada a casca (periderme) da planta de "barbatimão". O material foi submetido à secagem em estufa de circulação forçada a $45^{\circ} \mathrm{C}$ por período de $48 \mathrm{~h}$, logo foi moído em moinho tipo Wiley e submetido à extração por maceração estática usando etanol P.A. como solvente (1:2 de casca para etanol p/v respectivamente), em um período de oito dias (ZELNIK et al., 1977). O EBSSa foi obtido da separação do solvente por evaporação em estufa de circulação forçada a $45^{\circ} \mathrm{C}$ até ressecar totalmente (ORLANDO, 2005).

A atividade antimicrobiana foi determinada pelo método de difusão em disco (NCCLS, 2002), adaptada por Pinto et al. (2003), medindo os diâmetros dos halos de inibição formados (BARRY; THORNSBERRY, 1991). Os materiais vegetais em estudo foram diluídos em concentrações que variaram de 400 a $25 \mathrm{mg} / \mathrm{mL}$ em solução aquosa de dimetilsufóxido (DMSO) a 10\% e 320 a $20 \mu \mathrm{L} / \mathrm{mL}$ em solução aquosa de Tween $80^{\circledR}$ (propilenoglicol) a 10\%, respectivamente para o EBSSa e OELs (HOOD et al., 2003; KARAMAN et al., 2003). Discos de papel filtro (Whatman número 1) medindo $6 \mathrm{~mm}$ de diâmetro foram impregnados com as diluições e colocados na superfície de placas de petri contendo Agar Mueller Hinton previamente inoculado com uma suspensão bacteriana com turvação equivalente ao tubo 
0,5 da escala de Mc Farland. As culturas foram incubadas a $35 \pm 2^{\circ} \mathrm{C}$ por $18-24 \mathrm{~h}$ (CARVALHO et al., 2002). Como controle negativo usou-se disco impregnado com solução aquosa de DMSO a $10 \%$, Tween $80^{\circledR}$ a $10 \%$ e, controle positivo Vancomicina $30 \mu \mathrm{g}$.

A concentração bactericida mínima do EBSSa e OELs foi determinada pelo método de diluição seriada em tubos (RIOS et al., 1988). Cada cepa utilizada foi inoculada em caldo de BHI (Brain and Heart Infusion) e incubada a $35 \pm 2^{\circ} \mathrm{C}$ durante $18-24 \mathrm{~h}$. A partir deste inóculo, foi ajustada a turvação em salina até o tubo 0,5 da escala de Mc Farland e diluídas 1:10 em salina. Em seguida foram transferidos $100 \mu \mathrm{L}$ da suspensão padronizada para cada tubo de ensaio contendo $2 \mathrm{~mL}$ de solução de DMSO ou Tween $80^{\circledR}$, caldo BHI e o antimicrobiano em teste, para que desta forma a solução final contenha aproximadamente $5 \times 10^{5} \mathrm{ufc} / \mathrm{mL}$ (NCCLS, 2003). Diluições seriadas de base dois foram realizadas a fim de encontrar concentrações de 400 a $25 \mathrm{mg} / \mathrm{mL}$ para o EBSSa e 320 a $20 \mathrm{mg} / \mathrm{mL}$ para o OELs. Após incubação a $35 \pm 2^{\circ} \mathrm{C}$ por $24 \mathrm{~h}$, uma alíquota de cada tubo foi transferida para placas de Petri contendo meio sólido Müeller-Hinton, sendo incubadas a $35 \pm 2^{\circ} \mathrm{C}$ por 24h para posterior verificação de presença ou ausência de crescimento bacteriano (PIZSOLITTO; POZETTI, 1987).

Todos os testes foram feitos em triplicata, sendo conduzidos, simultaneamente, testes controle com as bactérias com o solvente DMSO a 10\% para o EBSSa e Tween $80^{\circledR}$ a $10 \%$ para OELs.

As bactérias avaliadas neste estudo foram Echerichia coli, Staphylococcus aureus e Staphylococcus aureus ATCC 25923. As duas espécies não ATCC foram isoladas do leite total de rebanhos (tanque) provenientes de unidades agrícolas familiares do norte de Minas Gerais. As amostras de leite foram coletadas em frascos descartáveis estéreis e transportadas em caixas térmicas $\left( \pm 4^{\circ} \mathrm{C}\right)$ até o laboratório, onde foram semeadas em Agar Sangue (ágar base para ágar sangue acrescido de $5 \%$ de sangue de carneiro desfibrinado) e ágar Mac Conkey e incubadas por $72 \mathrm{~h}$ em estufa a $35 \pm 2^{\circ} \mathrm{C}$. Os cocos Gram- positivos agrupados em forma de cachos, com morfologia indicativa de Staphylococcus sp., foram identificados utilizando os testes de catalase, coagulase conjugada em plasma de coelho (SILVA et al., 2001), novobiocina, hidrólise da trealose, uréase, inoculação em ágar Salt D-Manitol, $\beta$-glucuronidase, acetoína e presença de hemólise (BRITO; BRITO, 1999). Para a identificação da Echerichia coli foi utilizado o meio Rugai com lisina conforme as orientações do fabricante (RUGAI; ARAÚJO, 1968).

As médias dos halos da atividade antimicrobiana no teste de disco-difusão foram analisadas pelo teste nãoparamétrico de Kruskal-Wallis pelo software SAEG 9.1. A CBM foi expressa como sendo a menor concentração que não houve crescimento bacteriano em todas as repetições (SOUZA et al., 2007).

\section{Resultados e Discussão}

O OELs mostrou ter efeito inibitório em todas as espécies em teste (Tabela 1). No entanto, na concentração de $160 \mu \mathrm{L} / \mathrm{mL}$ foi observado a presença de halo de inibição em todas as espécies de bactérias em estudo, exceto para $S$. aureus, que foi inibida na concentração subsequente $(320 \mu \mathrm{L} / \mathrm{mL})$.

TABELA 1: Halos de inibição do crescimento (mm) do óleo essencial de Lippia sidoides (OELs) frente a bactérias isoladas de leite cru.

\begin{tabular}{|c|c|c|c|c|c|c|c|}
\hline \multirow[b]{2}{*}{ Bactéria } & \multicolumn{7}{|c|}{ Concentração $(\mu \mathrm{L} / \mathrm{mL})$} \\
\hline & $0^{*}$ & 20 & 40 & 80 & 160 & 320 & $\begin{array}{l}\text { Van } \\
* *\end{array}$ \\
\hline Escherichia coli & 0,0 & 0,0 & 0,0 & 22,0 & 23,2 & 26,0 & 27,3 \\
\hline $\begin{array}{l}\text { Staphylococcus } \\
\text { aureus }\end{array}$ & 0,0 & 0,0 & 0,0 & 0,0 & 0,0 & 8,2 & 18,3 \\
\hline $\begin{array}{l}\text { Staphylococcus } \\
\text { aureus } * * *\end{array}$ & 0,0 & 0,0 & 0,0 & 0,0 & 8,2 & 14,0 & 22,0 \\
\hline
\end{tabular}

*controle negativo: solução de caldo BHI e Tween 80 (10\%);

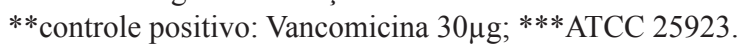

No presente trabalho, utilizou-se uma bactéria da espécie Staphylococcus aureus isolada do leite cru e outra da mesma espécie padronizada ATCC, portanto, obtidas em condições diferentes. Diante dos resultados dos halos de inibição do crescimento contidos na Tabela 1 , evidenciam a diferença da susceptibilidade das bactérias ao OELs, uma vez que a cepa padronizada foi inibida da concentração de $160 \mu \mathrm{L} / \mathrm{mL}$, enquanto que a cepa isolada do leite foi inibida da concentração de $320 \mu \mathrm{L} / \mathrm{mL}$. 
O OELs tem como principais compostos antimicrobianos o carvacrol e o timol (BOTELHO et al., 2007), esse ultimo já havia sido descrito por Myers e Thienes (1925) como sendo a substância de maior atividade leveduricida em análise de anti-sépticos, devido a sua grande capacidade de reduzir o número de células em menos de trinta segundos de contato. Em trabalho utilizando o OELs e seus principais constituintes (timol e carvacrol), Botelho et al. (2007) concluíram que houve inibição do crescimento das principais espécies de patógenos orais do gênero Streptococcus spp., assim como encontrado no presente trabalho, mostrando dessa forma, o OELs ter efeito inibitório sobre microrganismos originários de fontes diferentes.

Percebe-se que no teste de inibição pelo método de disco-difusão o EBSSa inibiu o crescimento de todas as bactérias na concentração de $200 \mathrm{mg} / \mathrm{mL}$ (Tabela 2), exceto para Echerichia coli que não foi inibida em quaisquer das concentrações, mostrando insensibilidade ao EBSSa.

TABELA 2: Halos de inibição (mm) do extrato bruto seco de Stryphnondendron adstringens (EBSSa) frente a bactérias isoladas de leite cru.

\begin{tabular}{|c|c|c|c|c|c|c|c|}
\hline \multirow[b]{2}{*}{ Bactéria } & \multicolumn{7}{|c|}{ Concentração (mg/mL) } \\
\hline & $0 *$ & 25 & 50 & 100 & 200 & 400 & $\begin{array}{l}\text { Van } \\
* *\end{array}$ \\
\hline Escherichi & 0,0 & 0,0 & 0,0 & 0,0 & 0,0 & 0,0 & 24,6 \\
\hline $\begin{array}{l}\text { Staphylococcus } \\
\text { aureus }\end{array}$ & 0,0 & 8,4 & 10,6 & 12,6 & 13,0 & 16,0 & 20,0 \\
\hline $\begin{array}{l}\text { Staphylococcus } \\
\text { aureus } * * *\end{array}$ & 0,0 & 10,6 & 11,2 & 13,2 & 15,2 & 16,0 & 22,2 \\
\hline
\end{tabular}

* controle negativo: solução de caldo BHI e DMSO a $10 \%$; ***ontrole positivo: Vancomicina $30 \mu \mathrm{g}$; ***ATCC 25923.

O EBSSa inibiu o crescimento da $S$. aureus e $S$. aureus ATCC na concentração de $25 \mathrm{mg} / \mathrm{mL}$, ou seja, na menor concentração em estudo, evidenciando a alta susceptibilidade desses microrganismo ao extrato vegetal.

A inibição do crescimento dessa bactéria pelo EBSSa é um fato importante, principalmente, por se tratar de um patógeno multiresistente à drogas utilizadas no tratamento da mastite bovina e ser um dos principais causadores dessa doença, tornando assim o
S. adstringens uma promissora fonte de antimicrobiano contra esse agente infeccioso (LOPES et al., 1990; BRITO; BRITO, 1999).

Audi et al. (2004) constataram que o extrato acetônico do $S$. adstringens inibiu o crescimento de $S$. aureus, porém, não inibiu a $E$. coli, atestando a insensibilidade desse microrganismo ao EBSSa que foi reportado também por Lopes et al. (2003).

No teste de concentração bactericida mínima o OELs apresentou efeito bactericida em todas as bactérias em estudo (Tabela 3), destacando a atividade do óleo sobre espécies do gênero Staphylococcus que ocorreu na concentração de $20 \mu \mathrm{L} / \mathrm{mL}$.

TABELA 3: Concentração bactericida mínima (CBM) do óleo essencial de Lippia sidoides (OELs) e do extrato bruto seco de Stryphnondendron adstringesn (EBSSa) frente a bactérias isoladas do leite cru.

\begin{tabular}{lcc}
\hline \multirow{2}{*}{ Bactéria } & \multicolumn{2}{c}{ Extrato } \\
\cline { 2 - 3 } & OELs $\mu \mathrm{L} / \mathrm{mL}$ & EBSSa mg/mL \\
\hline $\begin{array}{l}\text { Escherichia coli } \\
\text { Staphylococcus } \\
\text { aureus }\end{array}$ & 320 & $>400^{*}$ \\
$\begin{array}{l}\text { Staphylococcus } \\
\text { aureus } * *\end{array}$ & 20 & 400 \\
\hline
\end{tabular}

*: apresentou crescimento bacteriano em todas as concentrações; **ATCC 25923.

Em experimento realizado por Feitosa (2005), o OELs teve efeito bactericida na concentração de $20 \mathrm{mg} /$ $\mathrm{mL}$ sobre $S$. aureus e E. coli, confirmando a atividade bactericida desse extrato vegetal.

O EBSSa teve atividade bactericida para todas as bactérias na concentração de $400 \mathrm{mg} / \mathrm{mL}$, exceto à $E$. coli, que cresceu em todas as concentrações, mostrando ser resistente. Portanto, a CBM dessa bactéria deve estar acima de $400 \mathrm{mg} / \mathrm{mL}$ (Tabela 3 ).

Souza et al. (2007) verificaram concentrações bactericidas mínimas do EBSSa de 50 e $75 \mathrm{mg} / \mathrm{mL}$ para $S$. aureus, S. epidermitis e E. coli confirmando os resultados encontrados no presente estudo exceto para com $E$. coli que não teve $\mathrm{CBM}$ encontrada nas concentrações em estudo. No entanto, o trabalho supracitado foi realizado com bactérias de coleções de culturas, evidenciando 
a diferença da susceptibilidade dos microrganismos isolados de fontes diferentes nas avaliações de atividade antimicrobiana de novos compostos.

Os extratos vegetais mostraram-se potenciais agentes antimicrobianos frente às principais bactérias mesófilas encontradas no leite cru, no entanto, é necessário que estudos complementares sejam realizados para averiguar com mais segurança e de forma mais ampla as atividades e aplicações desses extratos para o uso animal e humano.

Conclui-se que os extratos vegetais possuem atividade antimicrobiana frente à todas as bactérias mesófilas isoladas de leite cru em estudo, exceto à $E$. coli para todos os testes quando foi utilizado o extrato de barbatimão.

\section{Referências}

AMABILE, J. M. Contribuição ao estudo da qualidade do leite pasteurizado por processo lento em condomínios leiteiros rurais. 1999. 63 f. Dissertação (Mestrado em Ciências dos Alimentos) - Universidade Federal de Santa Catarina, Florianópolis. 1999.

AUDI, E. A.; TOLEDO, C. E. M.; SANTOS, F. S.; BELLANDA, P. R.; ALVES-DO-PRADO, W.; UEDA-NAKAMURA, T.; NAKAMURA, C. V.; SAKURAGUI, C. M.; BERSANI-AMADO, C. A.; MELLO, J. C. P. Biological activity and quality control of extrat and stem bark from Stryphnodendron adstringens. Acta Farmaceutica Bonaerense, Buenos Aires, v. 23, n. 3, p. 328-333, 2004.

BARRY, A. L; THORNSBERRY, C. Susceptibility tests: diffusion test procedures. In: BALOWS, A.; HAUSER, W. J.; HERMANN, K. L.; ISENBERG, H. D.; SHAMODY, H. J. (Eds). Manual of clinical microbiology. 5 ed. Washington: American Society for Microbiology, 1991. p. 1117-1125.

BOtelho, M. A.; NOGUEIRA, N. A. P.; BAStOS, G. M.; FONSECA, S. G. C.; LEMOS, T. L. G.; MATOS, F. J. A.; MONTENEGRO, D.; HEUKELBACH, J.; RAO, V. S.; BRITO, G. A. C. Antimicrobial activity of the essential oil from Lippia sidoides, carvacrol and thymol against oral pathogens. Brazilian Journal of Medical and Biological Research, Ribeirão Preto, v. 40, p. 349-356, 2007.

BRITO, M. A. V. P.; BRITO, J. R. F. Diagnostico microbiológico da mastite. Juiz de Fora: Embrapa Gado de Leite, 1999. 26 p. (Circular Técnica, 55).

CARVALHO, A. A. T.; SAMPAIO, M. C. C.; SAMPAIO, F. C.; MELO, A. F. M.; SENA, K. X. F. R.; CHIAPPETA, A. A.; HIGINO, J. S. Atividade antimicrobiana in vitro de extratos hidroalcoólicos de Psidium guajava L. sobre bactérias gram-negativas. Acta Farmaceutica Bonaerense, Buenos Aires, v. 21, p. 255-258, 2002.
COHEN, M. L. Epidemiology of drug resistance: implications for a post-antimicrobial era. Science, Washington, v. 257, n. 11, p. 10501055, 1992.

FEITOSA, J. G. Avaliação antimicrobiana do óleo essencial de Lippia sidoides realizada pelo método de difusão em placa. In: REUNIÃO DA SOCIEDADE BRASILEIRA DE QUÍMICA, 28, 2005, Poços de Caldas. Anais... Poços de Caldas: SBQ, 2005. Versão eletrônica.

GERMANO, P. M. L.; GERMANO, M. I. S. Higiene do leite: aspectos gerais da mastites. Higiene Alimentar, São Paulo, v. 9, n. 16, p. 12-16, 1995.

GUENTHER, E. The essencial oils. Malabar: Krieger Publication Co., 1972. 427 p.

HOOD, J. R.; WILKINSON, J. M.; CAVANAGH, H. M. A. Evaluation of common antibacterial screening methods utilized in essential oil research. Journal of Essential Oil Research, Carol Stream, v. 15, p. 428-433, 2003.

KARAMAN, İ.; SAHIN, F.; GÜLLÜCE, M.; ÖGÜTÇÜ, H.; SENGÜL, M.; ADIGÜZEL, A. Antimicrobial activity of aqueous and methanol extracts of Juniperus oxycedrus L. Journal of Ethnopharmacology, Lausanne, v. 85, p. 231-235, 2003.

LOPES, C. A.; MORENO, G.; CURI, P. R.; GOTTSCHALK, A. F.; MODOLO, J. R.; HORACIO, A.; CORRÊA, A.; PAVAN, C. Characteristics of Staphylococcus aureus from subclinical bovine mastitis in Brazil. British Veterinary Journal, London, v. 146, n. 5, p. 443-8, 1990.

LOPES, G. C.; NAKAMURA, C. V.; DIAS FILHO, B. P.; MELLO, J. C. P. Estudo físico-químico, químico e biológico de extrato das cascas de Stryphnodendron poiyphyllum mart (Leguminosae). Revista Brasileira Farmacognosia, Curitiba, v. 13, supl. 2, p. 2427, 2003.

MACEDO, M.; FERREIRA, A. R. Plantas medicinais usadas para tratamentos dermatológicos, em comunidades da Bacia do Alto Paraguai, Mato Grosso. Revista Brasileira de Farmacognosia, Curitiba, v. 14 (Supl. 1), p. 40-44. 2004.

MARTINS, E. R.; CASTRO, D. M.; CASTELLANI, D. C.; DIAS, J. E. Plantas medicinais. Viçosa: UFV, 2000. 220 p.

MORAES, M. S. V.; ANDRADE, N. J.; CHAVES, J. B. P. Isolamento de esporos de equipamentos de abatedouros avícolas e avaliação de sua resistência a sanitizantes químicos. Ciência e Tecnologia Alimentar, Campinas, v. 17, n. 3, p. 325-328, 1997.

MYERS, H. B.; THIENES, C. H. The fungicidal activity of certain volatile oils and stearoptens. Their comparative toxicity on a pathogenic yeastlike organism: report of clinical utilization in related infections. Journal of the American Medical Association, Chicago, v. 84, n. 26, p. 1985-1986, 1925.

NCCLS. Performance standards for antimicrobial disk and dilution susceptibility test for bacteria isolated from animals: approved standard.Wayne, USA, 2002 (NCCLS document. M31-A2).

NCCLS. Methods for dilution antimicrobial susceptibility tests for bacteria that grow aerobically: approved standard. 6 ed. Wayne, USA, 2003 (NCCLS document M7-A6).

NORRBY, S. R.; NORD, C. E. Lack of development of new antimicrobial drugs: a potential serious threat to public health. Lancet Infectious Diseases, Solna, v. 5, p. 115-119, 2005. 
OLIVEIRA, F. P.; LIMA, E. O.; SIQUEIRA, J. J. P.; SOUZA, E. L.; SANTOS, B. H. C.; BARRETO, H. M. Effectiveness of Lippia sidoides Cham (Verbenaceae) essential oil in inhibiting the growth of Staphylococcus aureus strains isolated from clinical material. Brazilian Journal of Pharmacognosy, João Pessoa, v. 16, n. 4, p. 510-516, 2006.

ORLANDO, S. C. Avaliação da atividade antimicrobiana do extrato hidroalcoólico bruto da casca do Stryphnodendron adstringens (Martius) Coville (barbatimão). 2005. $89 \mathrm{f}$. Dissertação (Mestrado em Promoção de Saúde) - Universidade de Franca, Franca. 2005.

PINTO, T. J. A.; KANEKO, T. M.; OHARA, M. T. Controle biológico de qualidade de produtos farmacêuticos, correlatos e cosméticos. 2 ed. São Paulo: Atheneu Editora, 2003. 325 p.

PIZSOLITTO, A. C.; POZETTI, G. L. Avaliação comparativa da ação antibacteriana de tinturas-mãe de Thuya occidentalis. Revista Pesquisa Homeopatica, Ribeirão Preto, v. 3, p. 33-39, 1987.

RIBEIRO, A. Q.; LEITE, J. P. V.; DANTAS-BARROS, A. M. Perfil de utilização de fitoterápicos em farmácias comunitárias de Belo Horizonte sob a influência da legislação nacional. Revista Brasileira de Farmacognosia, Curitiba, v. 15, n. 1, p. 65-70, 2005. RIOS, J. L.; RECIO, M. C.; VILLAR, A. Screeening methods for natural products with antimicrobial activity: review of the literature. Journal of Etnopharmacology, Lausanne, v. 23, p. 127149,1988
RUGAI, E.; ARAÚJO, A. Meio de cultura para identificação presuntiva de bacilos Gram-negativos. Revista do Instituto Adolfo Lutz, São Paulo, v. 28, p. 79-83, 1968.

SANTOS, S. C.; MELLO, J. C. P. Taninos. In: SIMÓES, C. M. O.; SCHENKEL., E. P.; GOSMANN, G.; MELLO, J. C. P.; MENTZ, L. A.; PETROVICK, P. R. (Eds). Farmacognosia: da planta ao medicamento. Cap. 24. 2 ed. Porto Alegre: Ed. Universidade/ UFRGS/Ed. UFSC, 2000. p. 517-544.

SILVA, N.; JUNQUEIRA, V. C. A.; SILVEIRA, N. F. A. Manual de métodos de análise microbiológica de alimentos. 2 ed. São Paulo: Varela, 2001. 317 p.

SOUZA, T. M.; MOREIRA, R. R. D.; PIETRO, R. C. L. R.; ISAAC, V. L. B. Avaliação da atividade anti-séptica de extrato seco de Stryphnodendron adstringens (Mart.) Coville e de preparação cosmética. Revista Brasileira de Farmacognosia, Curitiba, v. 17, n. 1, p. 71-75, 2007.

TOLEDO, C. E. M. Estudos anatômico, químico e biológico de cascas e extratos obtidos de barbatimão (Stryphnodendron adstringens (Mart.) Coville, Leguminosae). 2002. $115 \mathrm{f}$. Dissertação (Mestrado Ciências Farmacêuticas) - Universidade Estadual Paulista, Araraquara. 2002.

ZELNIK, R. D.; LAVIE, D.; LEVY, E. C.; WANG, A. H. J.; PAUL, I. C. Barbatusin and cyclobutatusin, two novel diterpenoides from Coleus barbatus Benthan. Tetrahedron, Fort Collins, v. 33, p. 1457-1467, 1977. 